\title{
Circular Multifractal UWB monopole antenna
}

\author{
H. Ebrahim Zadeh ${ }^{\text {a) }}$, Ch. Ghobadi, and J. Nourinia \\ Department of electronics and communication, University of Urmia, Urmia57153, \\ Iran
}

a)St_h.ebrahimzadeh@urmia.ac.ir

\begin{abstract}
The novel circular Multifractal monopole antenna is presented for ultra-wideband (UWB) applications. The proposed antenna is etched on a FR4 substrate with the size of $22 \times 30 \times 1 \mathrm{~mm} 3$ and optimized to operate over the frequency band between 3 and $12.5 \mathrm{GHz}$. Keywords: circular monople antenna, Multifractal antenna, UWB Classification: Microwave and millimeter wave devices, circuits, and systems
\end{abstract}

\section{References}

[1] H. Wang and M. Zheng, "Triple-band wireless local area network monopole antenna," IEE Proc. Microw. Antennas Propag., vol. 2, no. 40, pp. 367-372, 2008.

[2] M. naghshvarian-jahromi, "Novel wideband planar fractal monopole antenna," IEEE Trans. Antennas. propag., vol. 56, no. 12, Dec. 2008.

[3] A. R. Harish and K. Joshi, "Studies on application of fractal based geometries in printed antenna structures," IEEE conference, 28-Dec. 2008.

[4] Ansoft high frequency structure simulation (HFSS), ver. 10. Ansoft Corporation, 2005.

[5] Manimegalai, S. Raju, and V. Abhaikumar, "A Multifractal cantor antenna for multiband wireless applications," IEEE Antennas. Wireless. Propage. Lett, vol. 8, 2009.

[6] G. Kumar and K. P. Ray, "Broadband Microstrip Antennas," Artech House, p. 46, 2003.

\section{Introduction}

In the last decades, there has been a huge evolution of the mobile communication systems. The most modern telecommunication systems require antennas with wide bandwidth and small dimensions. Microstrip-line-fed printed monopole antennas have received much attention because of their comparably wider operating bandwidth [1]. On the other hand, fractal antennas have been proposed for multiband or wideband applications [2] and [3].

In this paper, we propose a novel UWB printed monopole antenna with a circular multi-fractal structure.

The antenna performance is analyzed using high-frequency structure simulator (HFSS) [4]. Simulation and measured results are presented and com- 
pared.

\section{Antenna design and discussion}

The geometry of the proposed circular multi-fractal antenna is shown in Fig. 1 (a). It is etched on commonly used $1 \mathrm{~mm}-\mathrm{FR} 4$ with relative permittivity of 4.4 and has dimensions of $22 \times 30 \mathrm{~mm}^{2}$. The antenna is fed by a $50 \Omega$ microstrip line of width of $1.875 \mathrm{~mm}$ that is partially backed by a ground plane. The multi-fractal antenna is designed as shown in Fig. 1 (a). There is three segments of equal $\theta(=2 \pi / 3$ radian $)$ with a difference in the radios $\mathrm{r}$. Parametric studies of the effect of radios $R$ on the reflection coefficient of the proposed antenna is shown in Fig. 1 (b), while the other parameters are fixed according the given values. It is observed from Fig. 1 (b) that $R$ changes the resonant frequency ratios. So as $R$ increasing, the impedance bandwidth is increased and the impedance matching could be improved. Moreover the lower band-edge frequency decreases, as $R$ increases. As depicted from Fig. 1 (b), $\mathrm{R}=4 \mathrm{~mm}$ is the optimum value and the more increase of $\mathrm{R}$ to $4.5 \mathrm{~mm}$ increases the total antenna size. Because of the asymmetry structure of the proposed antenna, the feed line position $(D)$ is also affects the antenna per-

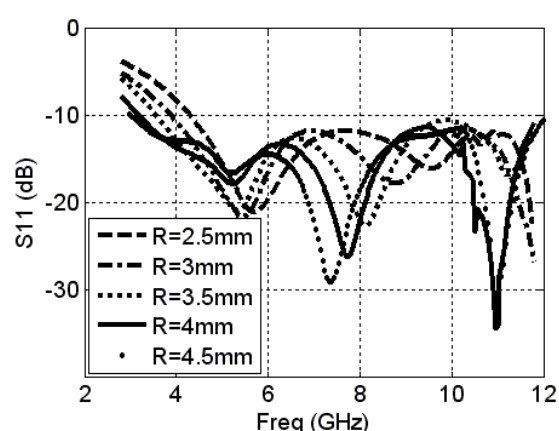

(a)

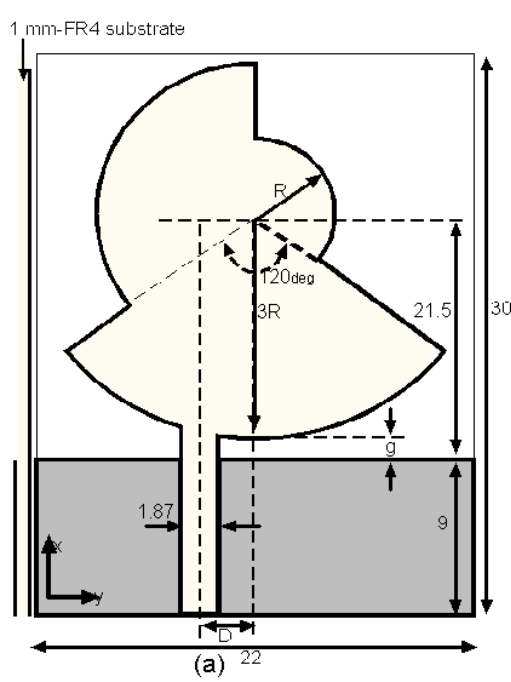

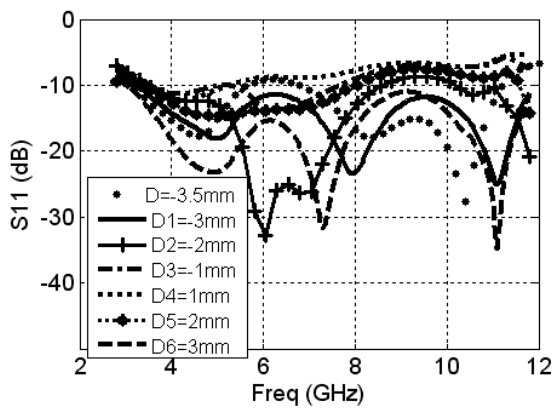

(c)

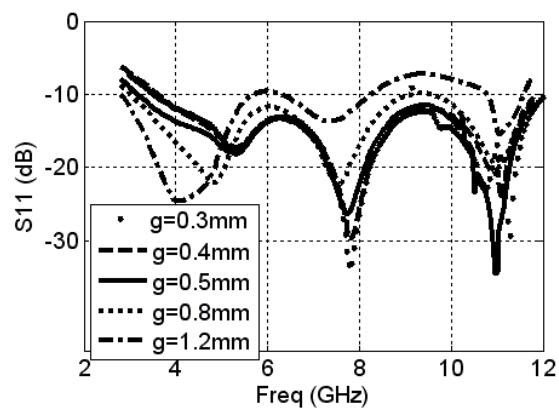

(d)

Fig. 1. (a): Geometry of the circular Multifractal monopole antenna $(\mathrm{R}=4 \mathrm{~mm}, \mathrm{D}=-3 \mathrm{~mm}$, $\mathrm{g}=0.4 \mathrm{~mm})$; Simulated reflection coefficient for the proposed antenna with different value of (b): radios $\mathrm{R} ;(\mathrm{c})$ : $\mathrm{D}$; (d): g. 
formance [5]. As shown if Fig. 1(c), the impedance matching in the overall operating frequency band and so the impedance bandwidth is increased with the absolute value of $D$ up to $3 \mathrm{~mm}$. As illustrated in Fig. 1(c), the more increase in absolute value of $D$ degrades the impedance matching. On the other hand, generally, the ground plane acts as an impedance matching circuit. As illustrated in Fig. 1(d), the gap width between the ground plane and radiating patch $(g)$ controls the impedance matching in the whole operating frequency band. As, shown in Fig. 1 (d), the antenna performance is fixed for the $g$ value between 0.3 and $0.5 \mathrm{~mm}$. As $g$ increases, the lower band-edge frequency decreases. As summary, the optimum values of the proposed antenna parameters are $\mathrm{R}=4 \mathrm{~mm}, \mathrm{D}=-3 \mathrm{~mm}, \mathrm{~g}=0.4 \mathrm{~mm}$.

\section{Experimental results}

The optimized antenna design is manufactured using the substrate FR4epoxy, shown in Fig. 2(a). The simulations and optimizations are based on Ansoft HFSS and an Agilent8722es network analyzer and soldered SMA connector and probe are used for the impedance measurements. The simulated and measured return losses for the proposed antenna are compared in Fig. 2 (b). For comparison, the antenna resonant frequencies in the measured

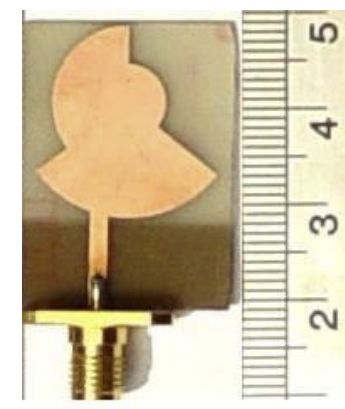

(a)

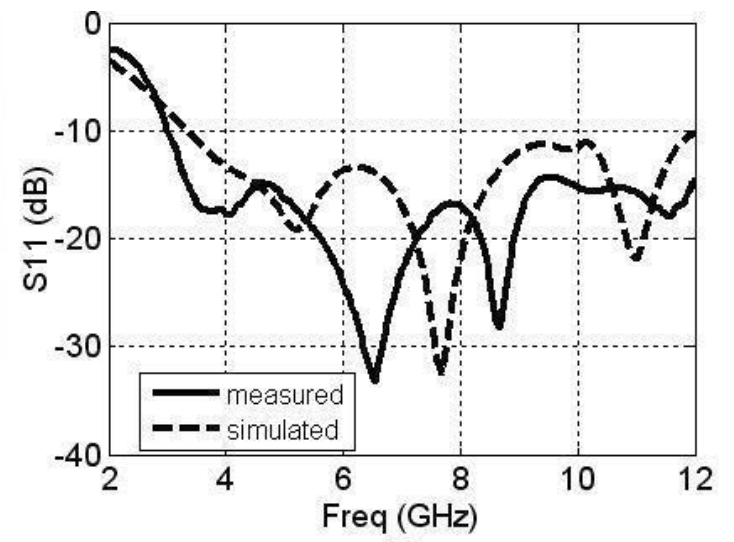

(b)

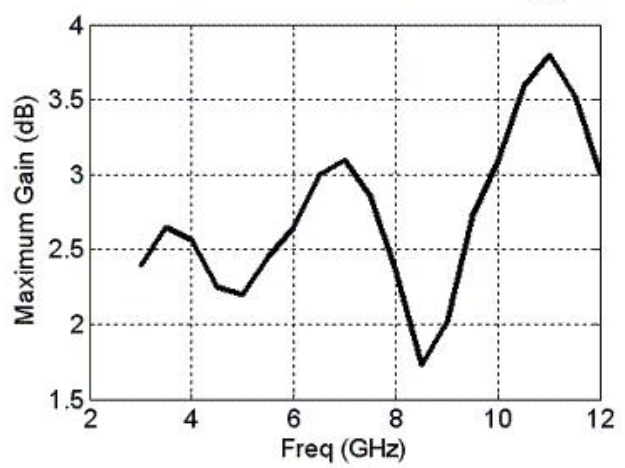

(c)

Fig. 2. (a) Photograph of the prototyped Multifractal UWB antenna; (b) Comparison between measured and simulated reflection coefficients of the proposed UWB antenna. (c) Maximum Gain of the proposed UWB antenna. 


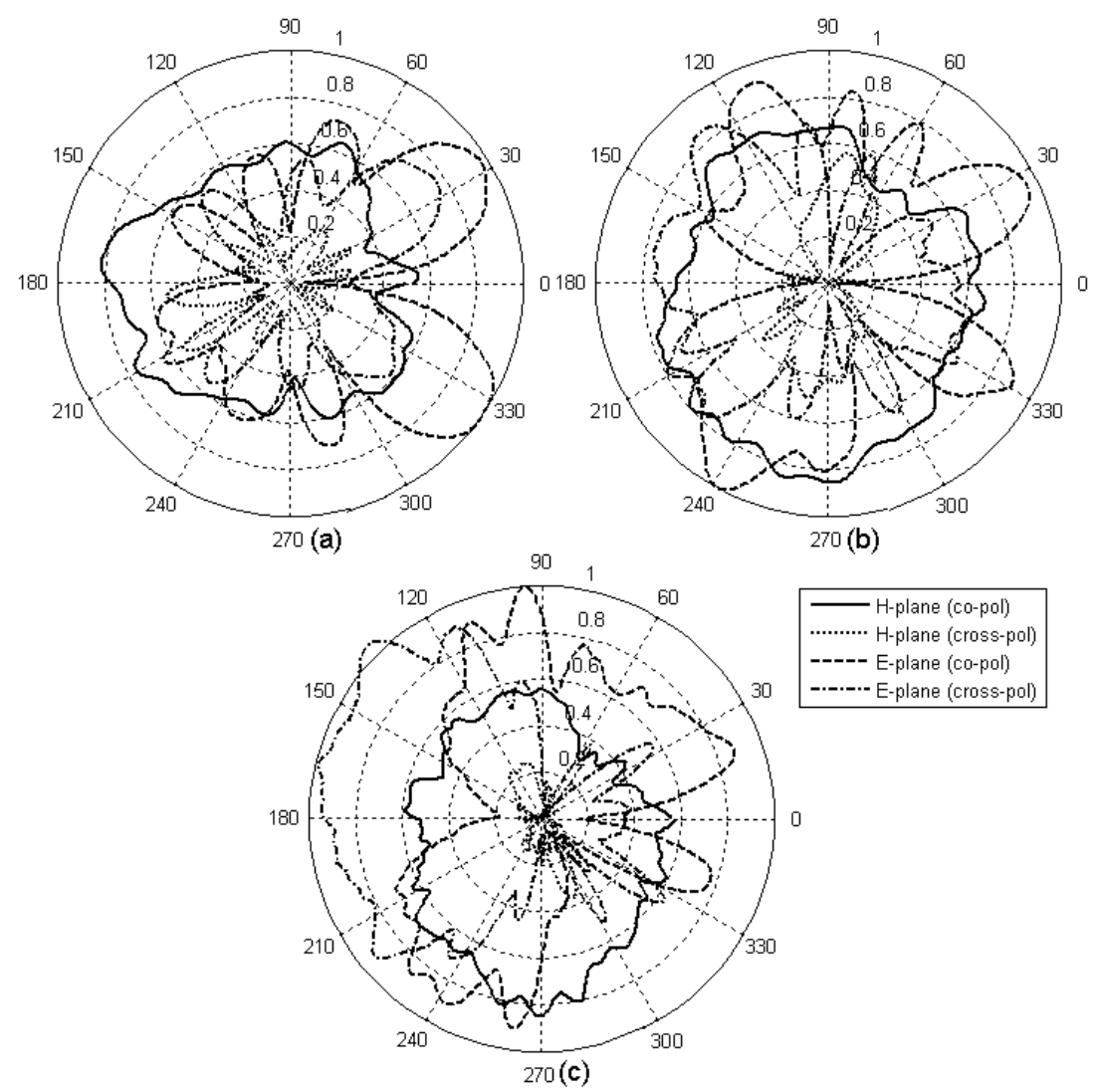

Fig. 3. Measured H-plane and E-plane radiation patterns for the proposed antenna at (a) $3.5 \mathrm{GHz}$; (b) $4.8 \mathrm{GHz}$; (c) $7.3 \mathrm{GHz}$.

result are shifted left mainly due to the inductance increscent effect of the fed probe, Generally, the probe is modeled as an inductor, because the impedance of the probe is predominantly inductive [6]. Therefore, the resonances get closer and the impedance matching is improved in the upper frequency band, however, this shift-effect is negligible for the lower band-edge frequency and the UWB performance of the proposed antenna approximately agrees with simulation analyzes result as the antenna operates in UWB frequency band from 3 to $12 \mathrm{GHz}$. Fig. 2 (c) shows the maximum gain of the proposed antenna. As illustrated, the antenna gain changes between $1.7 \mathrm{~dB}$ and $3.7 \mathrm{~dB}$ in the operating frequency band so the antenna gain is nearly flat in the overall frequency band. The measured radiation patterns in the H-plane and E-plane at 3.5, 4.8 and $7.3 \mathrm{GHz}$ are plotted in Fig. 3. The H-plane pattern of the antenna is approximately omni-directional for all in-band frequencies. Also, in the H-plane, the cross-polarization of the antenna increases with frequency. Concerning the E-plane pattern, Fig. 3 also shows that the antenna behaves quite similarly to the typical printed monopole antennas in the in-band frequencies with some ripples, considering that the ripples get smoother in the upper frequency band.

\section{Conclusion}

A small band-notched printed Multifractal monopole antenna has been pro- 
posed for UWB applications. It is demonstrated that in the antenna bandwidth controls with the radios $\mathrm{R}$ and the feed line position improves the impedance matching. So the presented antenna exhibits a broad impedance bandwidth and good impedance matching from 3 to $12 \mathrm{GHz}$.

\section{Acknowledgments}

The authors would like to thank Iran Telecommunication Research Center (ITRC) for financial support and its Antenna Lab where the proposed antenna has been tested. 